\title{
The Future of Architectural Education in Egypt " Architecture Pedagogy Focuses on Educational Concepts and Approaches"
}

\author{
${ }^{1}$ E. A. Aboushal \\ Assistant profesor at High Institute of Engineering and Technology (BHI),Architectural Department,Egypt. \\ Esraaaboushal1@gmail.com.Phone:+201289931406 \\ ${ }^{2}$ Mohamed Salah Gharib \\ Assistant profesor at High Institute of Engineering and Technology (BHI),Architectural Department,Egypt. \\ mohds69@gmail.com.Phone:+2 01222640690
}

\begin{abstract}
Architectural education in Egypt is not used the advanced methods yet e.g., digital studio, simulation methods, and virtual reality technology. Thus, this paper proposes a new method for updating the future education of architecture to be more qualified and smarter for architectural students such as applying virtual reality technology (VR). Furthermore, VR depends on various tools and systems such as, Computer Aided Virtual Environment (CAVE system) that presents the third dimension of space to be realized with all details. The proposed method is shown to benefit the architectural students, whether at the level of study or in keeping pace with the labor market in the future. In this track, virtual education can be applied specially in particular theories and history of architecture. Therefore, the architectural students can improve their sense of spaces, proportions, materials, textures, lighting, masses of buildings and all other needed functions. Moreover, VR model of historical site is proposed in this paper as a case study by using the CAVE system to enrich the architectural education especially in the course of architecture history and at the local level in Egypt. Therefore, architectural students can perceive all the design principles in 3D virtual environment (VE) as the perception of different spaces by immersing in virtual world. This saves time and effort instead of visiting the real sites under study besides saving the cost of travel and transitions. To verify the effectiveness of the proposed solution, a detailed case study has been applied on Elselsla area, which is located in Alexandria governorate in Egypt. This study area ia selected to be re-designed as a renovation of historical area with competency and outperformance according to the architectural theories and design principles.
\end{abstract}

\section{Keywords}

Virtual Reality (VR), CAVE system, Virtual Environment (VE), Virtual Models.

\section{Introduction}

Virtual Reality technology is the most important technique reached by the technological revolution; it had a significant impact in various fields of life. In addition, this technology is used to develop various architectural fields such as architectural design, the future of architectural education especially for the development of studies courses such as, the history of architecture and theories of architecture with the latest technological methods. This has been done through presenting; analyzing the virtual models that enables users to be totally immeresed in 3D virtual environment (VE) with more realistic effects and fully perception. VR has been developed as a reference model for simulating the architectural projects whether they are inside or outside the 3D buildings by simulating the architectural sites that include these buildings to be studied for students. This procedure will be helpful especially in those places that are difficult to move in different countries which contbuting in saving time, effort and helping to increase the imagination and enrich the importance of architectural information for the students. Further, VR technology is a multi-platform application which includes CAVE system that depends on using Head Mounted Display (HMD), Data Gloves and navigation tools,.... etc.). In addition, VR technology integrates with different technologies spatially in supporting the rehabition of historical sites as laser scanning and point cloud. Moreover, this integration helps architects in improving various construction and proposed design scenarios to produce accurate urban and design projects. Also, perceiving any historical sites or any building that has been constructed according to architectural theories. This procedure is achieved in accurate presentation of the location, colors and scales for simulating, evaluating any historical area in the VE and finally, re-design it at a very high resolution. Moreover, defining different angles in every virtual scene with all zooming tools as showed in Fig.1. 

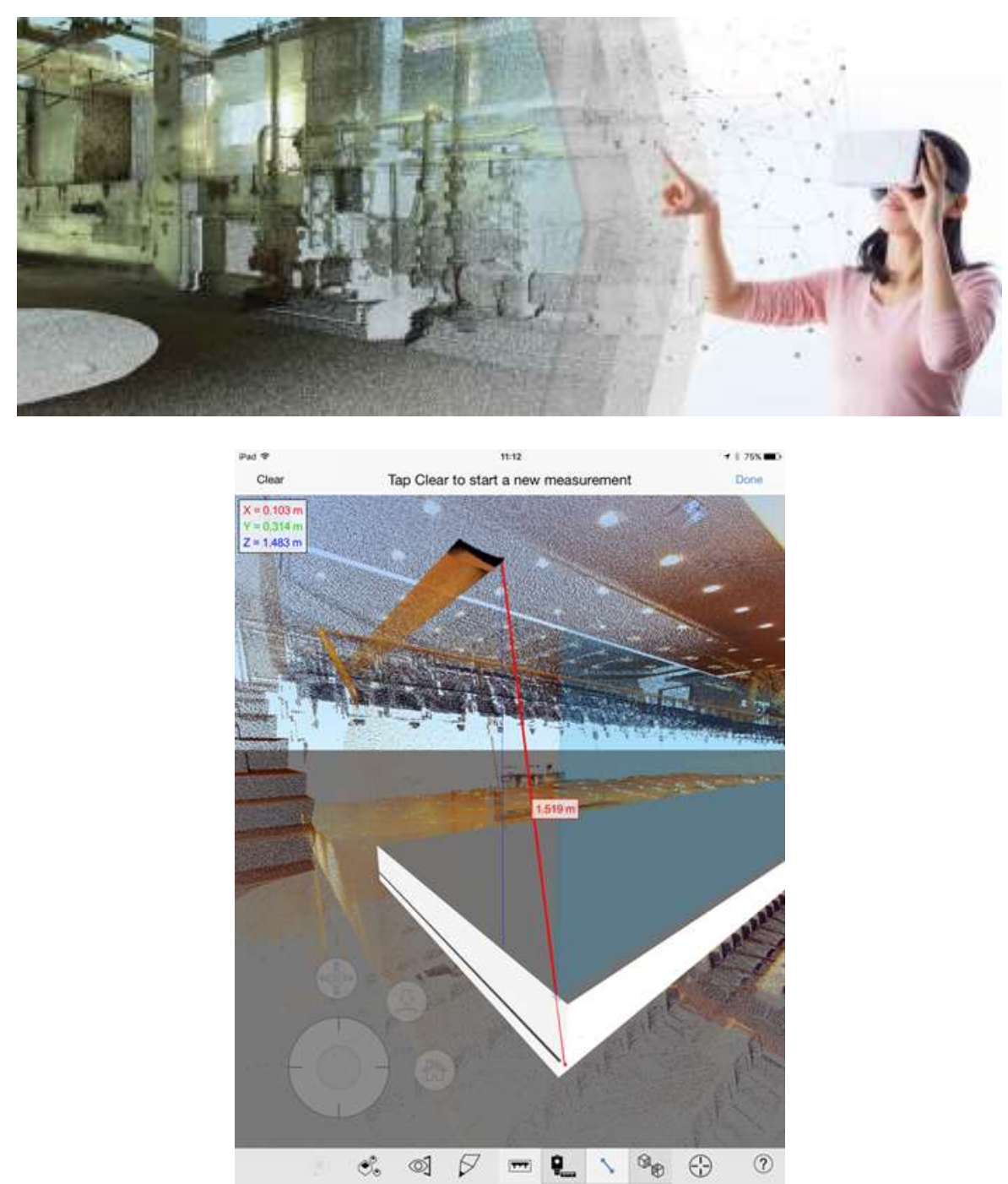

Fig.1. Using integrated technologies of VR and point cloud in the survey analysis of internal historical buildings.

Top: Redesign a historical building by using VR and point cloud to detect the high of points.

Bellow: Identifying the distances between the design elements and the point cloud out on site using the metadata measurement tool.

As per the aforementioned, the architect applies the VR technology in the design process to study the proposed design with full details, analyse all parts and components of architecural projects whether from the perspective form or function at different angles in the fourth dimension (4D). This procedure formulates the research problematic in this paper and achieves a better understanding with more precisely the composition of the spaces, shapes, colors and architectural fabric process. But at the same time, the design that presented by using VR technology requires putting the proper architectural theories of the new design framework, which starts from the architecture point of view and then fits into the input of special software to output a VE and not vice versa. So, this technology has put a new light on the debate between science and art in architecture. Where, the scientific approach focuses on the information that appears as project data, and the artistic approach focuses on inner information as the sensitive understanding of content.

Further, an important aspect of VR-based systems is the stimulation of the human senses, typically sight, sound, and touches, such that a user feels a sense of presence (or immersion) in the VE. Moreover, VR's approach presents the virtual learning of architectural education, and emerging learning theories. The paper then moves to clarify the importance of the problem by conducting a survey among architectural students. On this track, many researches have been introduced to present the role of VR in architectural educdation at diffrernt fileds using virtual reality systems and tools. Primarily, improving major urban development projects of virtual cities, E-Planning that have been widely applied in the architectural education (Afrooz et al. 2018). (Tran et al. 2018) use virtual 3D city models to simulate city development by rich point clouds. In 2020, Riga, Latvia have been studied the development of a virtual model for a replication of a real-world study in the Seattle Central Library by modeling the virtual environment, optimizing the performance, and designing the humanenvironment interaction (Kuliga et al. 2020). 
Same concept has been discussed by (Maghool, Moeini, and Arefazar 2018), where challenges in teaching architecture including the review of historical periods of ancient cities for history courses, and also involving design studios and their complicated image production challenges have been observed. In addition, those researches lack the integration of the technical and conceptual restrictions that remarkably influence the fully immersive virtual environments as CAVE system. In particular, they lack the advanced visualization and rendering techniques, such as satisfactory real-time photorealistic rendering, assistive interaction techniques, an immersion-supporting sound scape, and thus in many cases do not meet the expectations of stakeholders.

This motivates an alternative approach that considers comprehensiveness analysis of integrated technologies with VR. The 3D software giants have integrated their 3D experiences allowing the users enriching perspective on their 3D designs. Therefore, following the research problematic and motivations, this paper presents a new technical concepts of a system for visualizing virtual 3D models, fully immersive environments for architectural education with helping of the CAVE system. Hence, this new system is proposed to help in upgrading the architectural education process. Additionally, CAVE system enables exploration and analysis of 3D models by multiple users in an intuitive and collaborative way. Based on the above presented data explained, the problematic modeling of 3D virtual model is facilitating the perception process of space and their 3D buildings with full architectural details. 3D virtual model has various relationships between the contained architectural features. Also, the 3D virtual model can be generated using various integrated software such as; Autodesk AutoCAD®, Google Earth imagery®, 3D max®....etc, specially on local levels as in Egypt. Moreover, the 3D virtual model authorizes users to navigate, evaluate any virtual space, whether it exists or need future extensions. This helps architects and different specialists to exchange the different data at accurate method.

The research aims to demonstrate the improvement in perciption of the space with all 3D details in a VE by adopting the technological developments in the virtual world. The latter could be achived by percepting a local experience of an immersive VE conducive to the recipient's understanding of the architectural space and its properties. To achieve this aim, the research follows these steps:

Developing a comprehensive theoretical framework by presentating the most important factors affected in the receiver perception. Also, spoting on the properties of perceived characteristics of virtual space to identify the most important items that affect the process of cognition.

Creating a VE model using the CAVE system and applied to an architectural project designed by the authores in the history of architecture field.

Measure the level of awareness of the recipient when using the CAVE system that have been created in this research by comparing this technological system to the normal computer screen technology.

\section{Methodology of the Paper}

This section presents the methodology of the proposed VR model of different historical buildings in Elselsla study area that located in Sharq district at Alexandria governorate at Egypt. The study area needs to redesign because the urban space is neglected in terms of recreation and tourism activity. This usage is activied through applying the VR model that proposed for improving its current un-organized planning using the CAVE system. These procedures are handled using various geospatial software, including Google Earth imagery ${ }^{\circledR}$ and 3D Studio Max ${ }^{\circledR}$. According to the aforementioned, the proposed methodology is addressed through three main stages which adopted for the implementation of the proposed method as follows. Firstly, the research depends on putting a theoretical framework that presents the concept of applying the VR technology in architectural model by using the CAVE system. Secondly, 3D virtual model is addressed according to the definition of the most important factors affecting the perception of the receiver and the most important perceived characteristics of space. Thirdly, the research then moves on doing the practical case study which includes integrated steps from planning to design step by creating a virtual model using the CAVE system. The virtual model determines the technical efficiency which compared to the conventional computer screen technology in the design process.

\subsection{First Stage}

Identifying the study area after surveying process on the base map at Google Earth Software.

Step (1): Analytical study is implemented for site determination and its allocated buildings as bibliotheca Alexandrina (site analysis).

Step (2): Analysis of spatial relationship in the study area to take the decisions of design.

Step (3): Identifying the urban problems emerged within the studied study area, which consequently assist on figuring out the required services, such as restaurants and cafe, bazaars buildings, seatings areas, places of walking and navigation. 


\subsection{Second Stage}

The modeling process of the proposed virtual model is well defined to provide a comprehensive process starting from the planning of the historical site to the design process related to the proposed buildings. This modeling is produced with various steps using integrated software as Autodesk AutoCAD® and 3D max ${ }^{\circledR}$ as per the following steps.

Step (1): The integration between surveyed model in AutoCAD® software and exporting 3D model in 3D $\max \circledast$ software at $3 \mathrm{ds}$ format.

Step (2): 3D analyzed model to determine the needed spatial relations between borders and the 3D proposed buildings.

\subsection{Third Stage}

In this stage, virtual model is employed as a main part of the experimental CAVE system, which is used to simulate the 3D proposed historical site. Then, students navigate in the virtual site to study and analyze the proposed design. After that, every student expresses his/her percepting of the historical site in a standard form about all details of design, material, circulation system in the new designed site.

\section{Overview of the Case Study}

Elselsla Square is one of the historical areas which located in Alexandria governorate at Egypt in the Azarita at Sharq district has been selected as the case study in this paper. The site overlooks the sea and in front of the Bibliotheca Alexandrina. In addition, the site includes the sculpture of the sails, by the Egyptian sculptor Fathi Mahmoud. Moreover, the historical site includes the remains of Alexandria's Greek walls that were discovered under the waters of the chain, as well as the remains of pillars, crowns and silver coins. Its total area is about $53,000 \mathrm{~m}^{2}$ which is shown in Google Earth imagery® software, as illustrated in Fig.2. In addition, the historical site needs to redesign according to the proper criteria of design and planning to be activated as a recreational use and as a historical revival of the site.

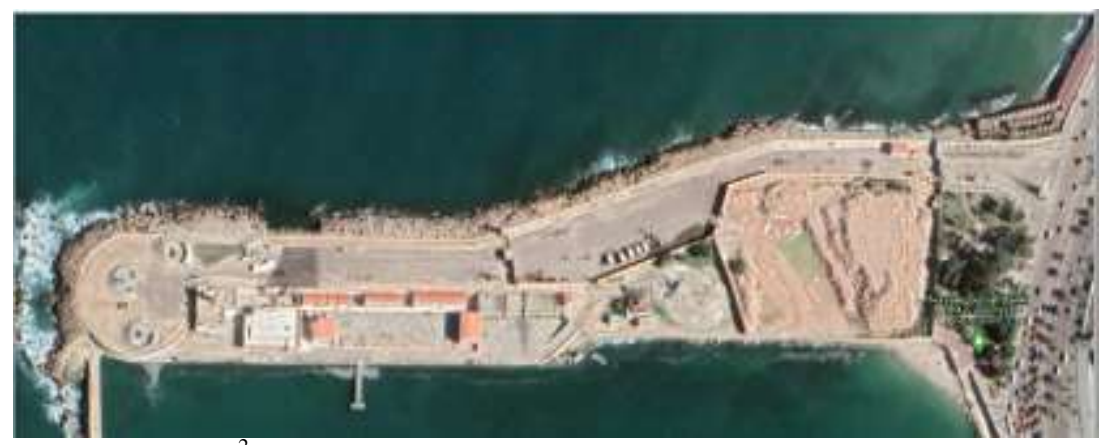

Fig.2: The study area equal $53,000 \mathrm{~m}^{2}$ which located in Google Earth imagery ${ }^{\circledR}$ software.

\subsection{The Proposed Design}

There are several strategic operations that have the mental considerations in design as in Fig 3, they are:

- Technical performance of information (theories, applications).

- Functionality of design elements.

- Creative performance of formation elements for proposed virtual urban spaces (VUS).

- The process of visualizing the design process within VE.

- Performing the simulation test, analysis and evaluation of the proposed design.

The proposed design includes two stages that simulate the historical eras of Alexandria from modernism to classique to brighten students' perceptions. This procedure helps the students to reach the most ancient historical ages and merge with them according to the architecture history courses. The design begins with the modern era of Alexandria by facing the library of Alexandria, which belongs to Ptolemaic dynasty. Then, users start their navigation through VUS passing by the next era (Greek) which the king alexander the great entered Alexandria city as illustrated in Fig.4. 


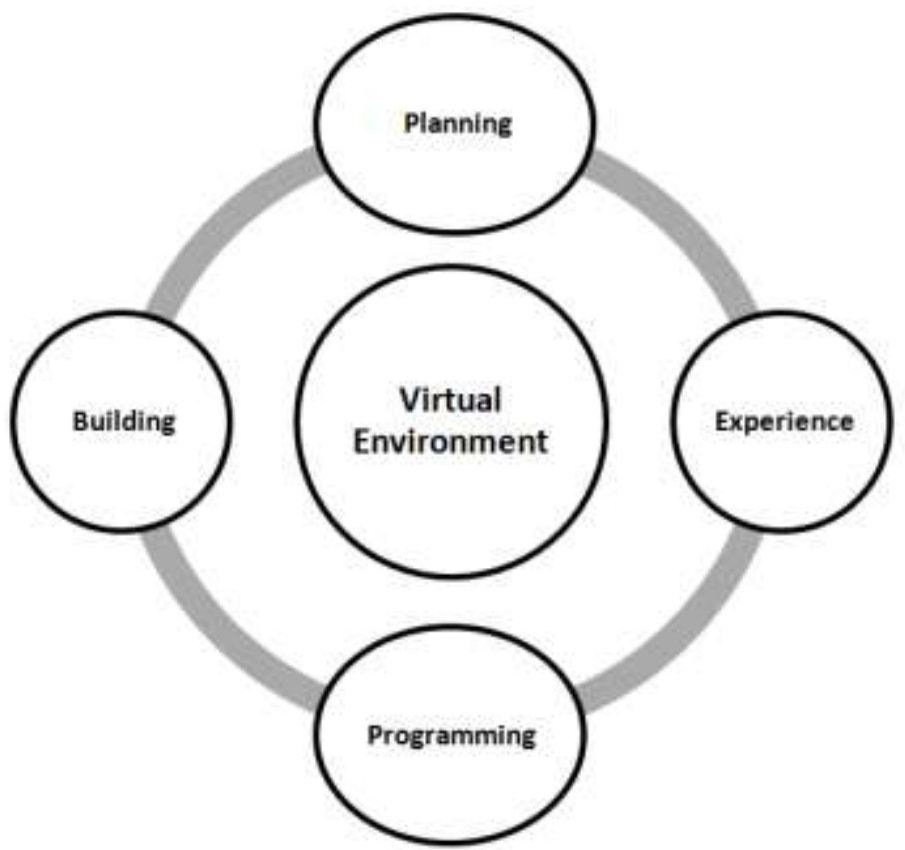

Fig.3. Development stages of building the Virtual Environment for studying the simulated historical site.
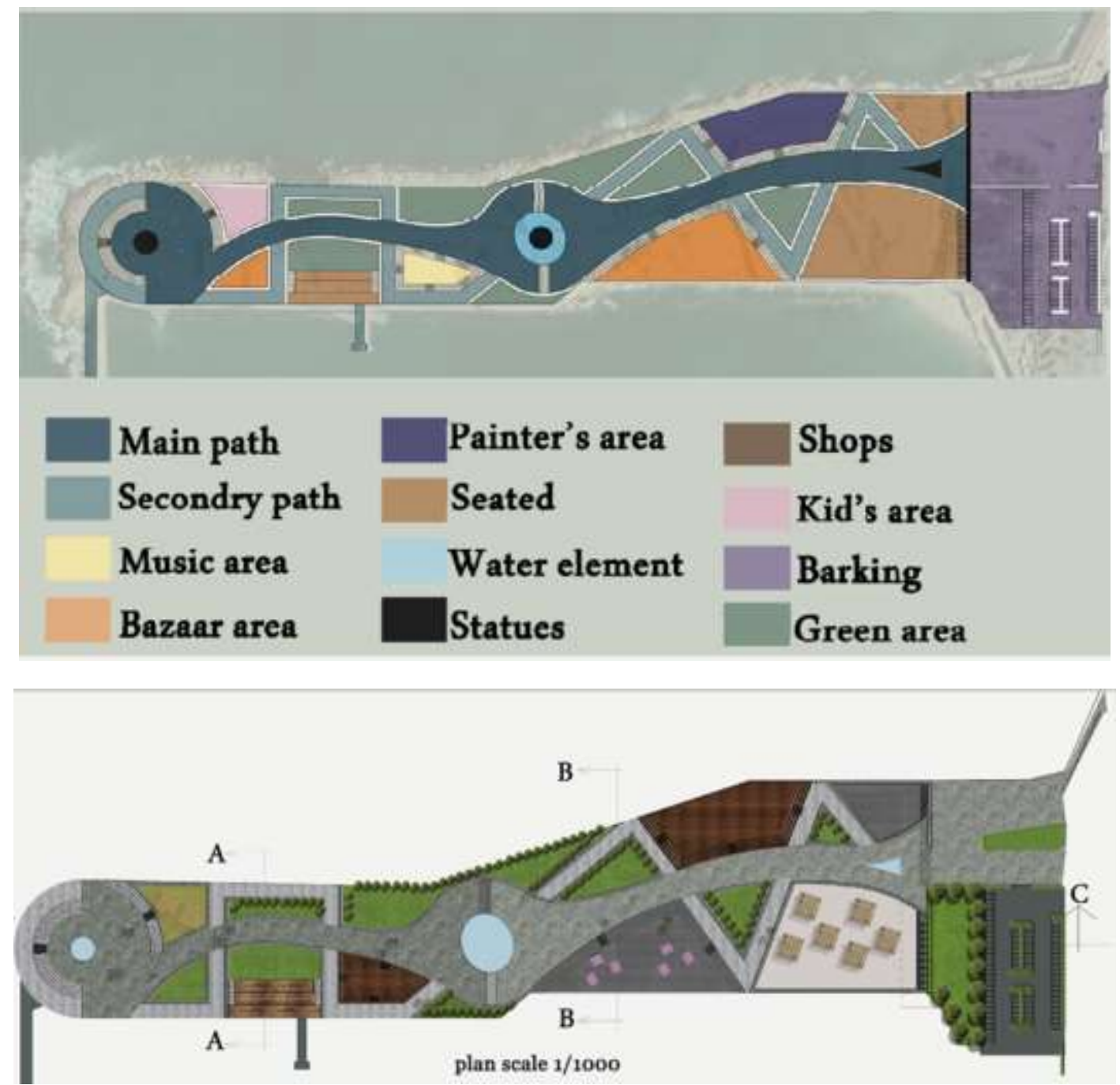

Fig.4: The proposed design includes all activities and seating areas by passing the historical eras.

Top: The proposed design zoning.

Bellow: The proposed design includes all functions and needs activities to rehabilitate the historical site. 


\subsection{The Perception of Proposed Virtual Space}

VUS which has been created in VE to help students acquiring cognitive, physical and social skills when they study the different historical era in various scenarios. The proposed design of interactive spaces demonstrates the perceptual abilities during navigation process of students and defining their interaction with the VUS and its activities and needed services as shown in Fig.5, Fig.6 and Fig.7. The perceived characteristics of VUS represent in site coordination of design elements such as different designed seating areas, lighting, signs, shops, bazaars. Besides, perceiving the proportions of the different designs and their relationship to urban spaces and green surfaces. Also, recognizing the vertical and horizontal transition elements of the proposed design.
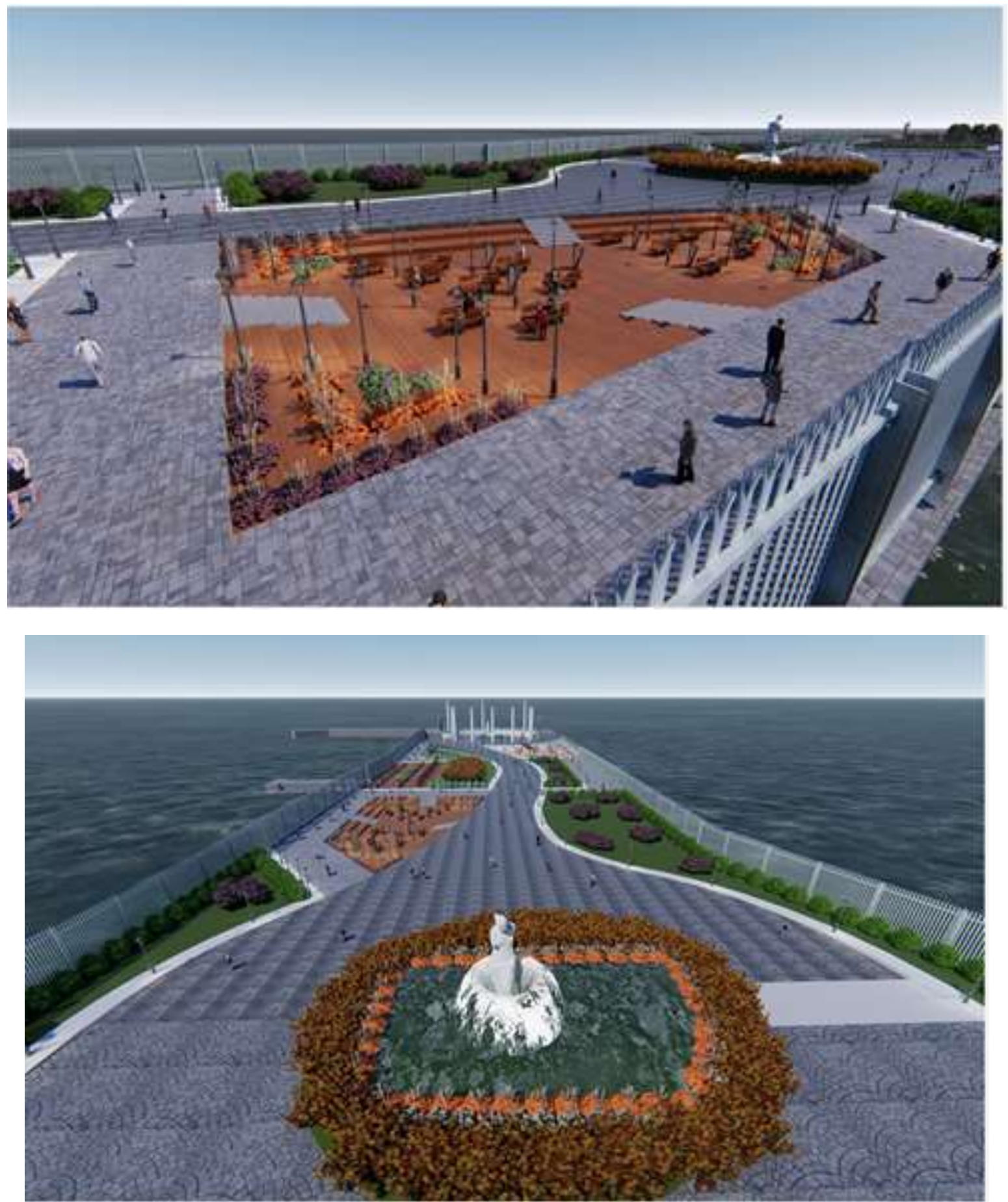

Fig.5. The proposed design of modern era of Ptolemaic dynasty as interactive spaces.

Above: Analysis of navigation path that surrounds the seating areas.

Below: Taking a virtual tour of a virtual interactive status as a land mark of Ptolemaic dynasty. 
${ }^{1}$ E. A. Aboushal, ${ }^{2}$ M. S. Gharib/ Engineering Research Journal 171 (Septemper 2021) A47-A58
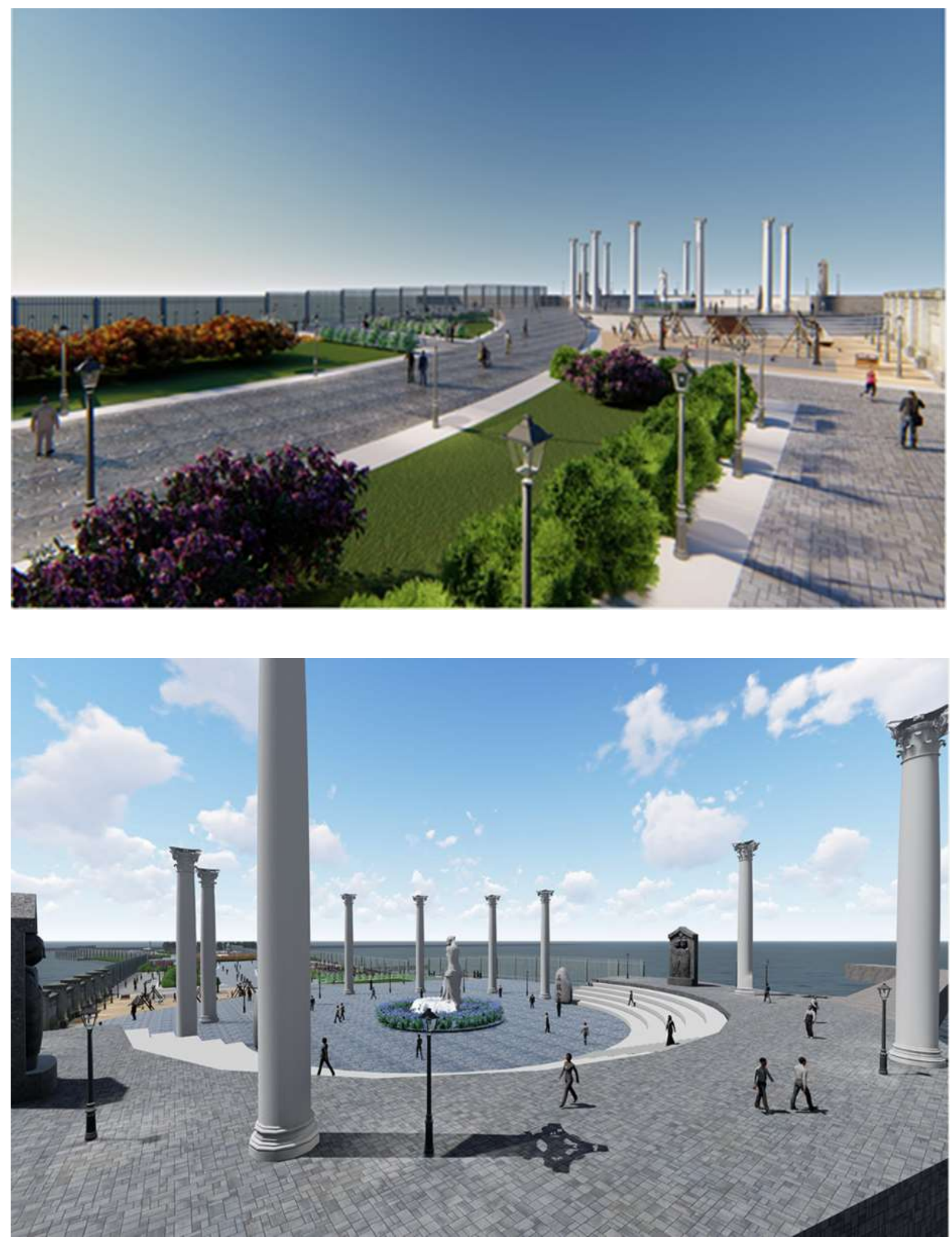

Fig.6: Percepting the proposed virtual design.

Top: The redesigned path reached from the modern era to the classical Greek era.

Bellow: The simulated roman theater as a gathering location and activated area. 

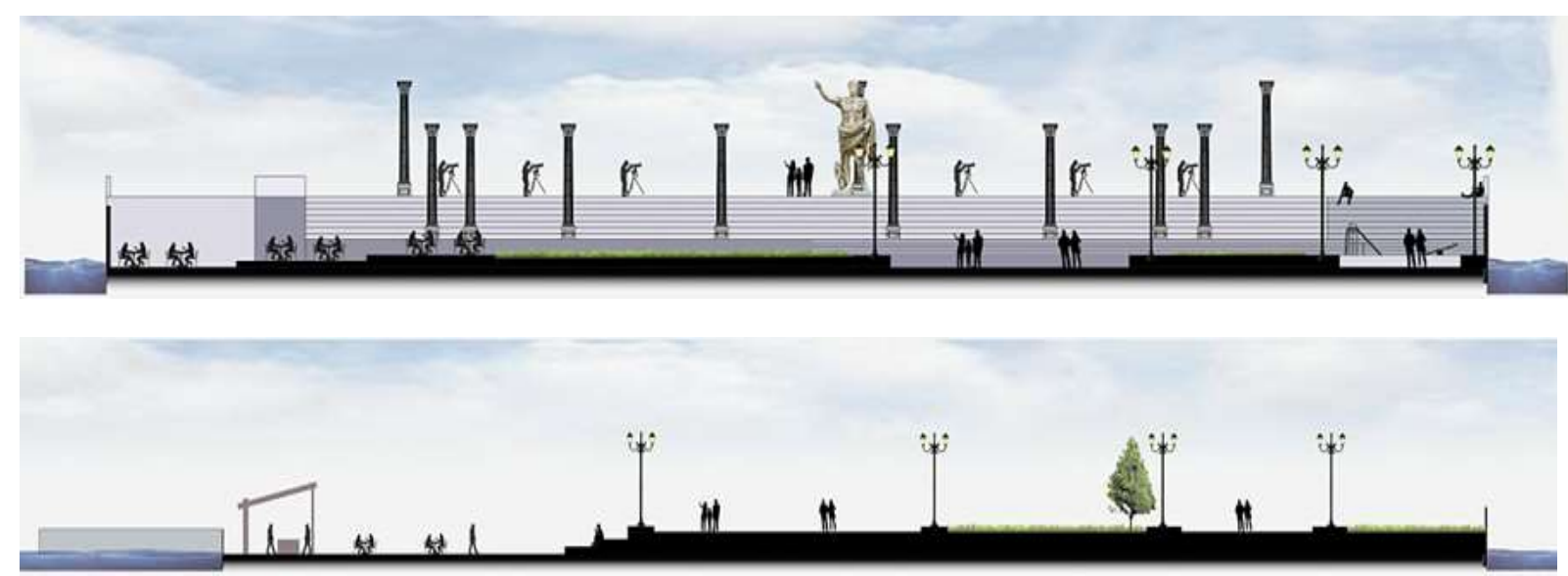

Fig.7: Architectural sections include the different historical eras.

Top: Section A-A includes the simulated roman theater and its spaces and seating stands.

Below: Section B-B includes various levels, the historical eras from Ptolemaic dynasty to the Greek and gathering spaces.

\subsection{Using the CAVE System for Creating a Virtual model of Elselsla}

The 3D virtual model of Elselsla has been created using the CAVE System to support the use of an interactive VE, which is based on the information database. Consequently, the architectural students address the proposed design through the formation of intellectual tendency using the automated capabilities of the computers, which is consider as exchanging of information and management of the design tool using multi components such as in Fig 8.

1- Users.

2- Input devices (computer hardware and software).

3- Input Data.

4- Output Data.

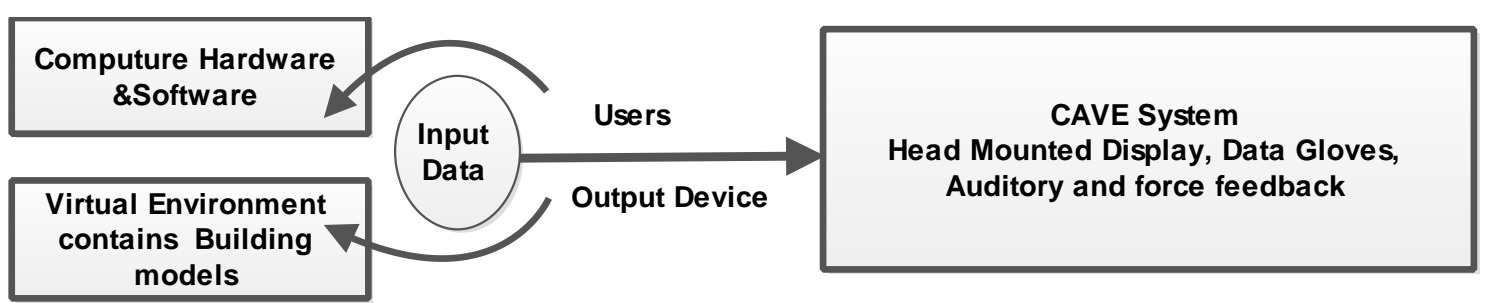

Fig.8. Integrating multi components within the virtual environment.

\section{- Performance Test for Digital Analysis of the Proposed Design}

Architectural students analyze the virtual model within its design and creative aspects for performing the digital design analysis that is done in the VE within the design project database. It is the process of testing the virtual model after the performance of design and before implementing it in the real world as shown in Fig.9 that achieves the various needed functions and intellectual trends in the design process as follow:

a. Providing open spaces with different activities as bazaars, shops, music areas, painter's area, kid's area and pecise geometrics of 3D monuments that express of historical eras using 3ds Max software.

b. The accurate visualization for the 3D virtual model illustrates the distributions of activites, partitions of land space and gives clear ideas for users to navigate through the historical site to support the decision-making for the redesign process. 


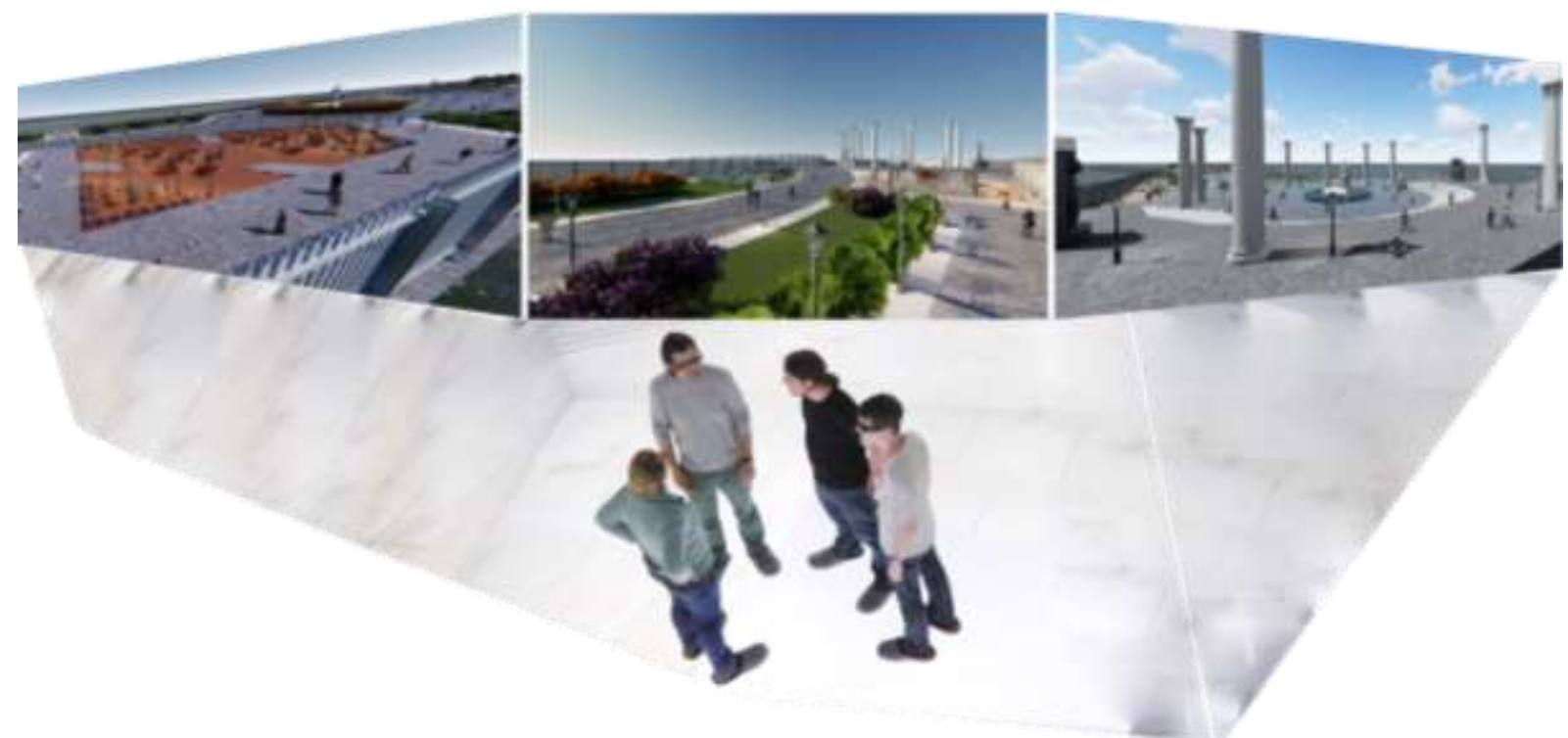

Fig.9. Architectural students using CAVE System after its operation in the lectures of the architectural theory by navigating into the proposed historical site of Elselsla and then evaluate it.

\subsection{Questionnaire of Students' Opinion for Using CAVE System in Studying the Redesigned Historical Site}

Using VR technology to simulate the historical eras enables the students to conduct many experiments to test the implementation of the architectural theories on the design of architectural projects under study. Also, virtual model enables the students in evaluating the production of redesigned architectural projects in a new and innovative way that illustrated in Table 1.

Table 1. Questionnaire of Students' Opinion for using Virtual Reality Technology in historical studies

\begin{tabular}{|c|c|}
\hline $\begin{array}{ll}\text { Ability } & \text { to } \\
\text { Experiment }\end{array}$ & $\begin{array}{l}\text { - Achieving the required functions and simulating the exterior beauty of the historical } \\
\text { buildings accuratly. } \\
\text { - The simulated architectural buildings according to defined historical era helps in } \\
\text { imagination of the Architectural vocabulary and perception of virtual spaces as if there } \\
\text { were real old. } \\
\text { - Using CAVE system helps students to navigate in the virtual model with free } \\
\text { movement to evalute the proposed design before implementing it in real world without } \\
\text { any errors or problems that may appear after the implementation and operation of real } \\
\text { site. }\end{array}$ \\
\hline $\begin{array}{l}\text { Visual } \\
\text { Inforn }\end{array}$ & $\begin{array}{l}\text { VR technology can improve the method of dealing with information, the ability to increase } \\
\text { its acquisition and delivery in a more clear and precise way to produce innovative and } \\
\text { advanced architectural projects specially the redesigned projects such as historical. }\end{array}$ \\
\hline $\begin{array}{c}\text { Facilitating } \\
\text { Communication }\end{array}$ & $\begin{array}{l}\text { Virtual architectural projects enable users in better communication between different } \\
\text { disciplines. Also, making design decisions faster and better than the traditional } \\
\text { methods. Thus eliminats the constraints of time, spatial boundaries and helpes in producing } \\
\text { more accurate projects with effective results. }\end{array}$ \\
\hline
\end{tabular}

\subsection{Suggesting the Framework of Upgrading Architectural Education}

The paper suggests various integrated points for creating a proposed framework as mentioned in Fig.10 that concerns the upgrading of the architectural education as theories of historical courses according to the following points:

1. Illustrating the process of visualizing the virtual model to activate the historical area under study culturally and historically.

2. Developing of the local community and upgrading in different fields such as, social, health, economic, educational and cultural,..etc.

3. Investment of the historical sites in coordination with the Ministry of Antiquities and with the development of the archaeological areas within the available resources. 


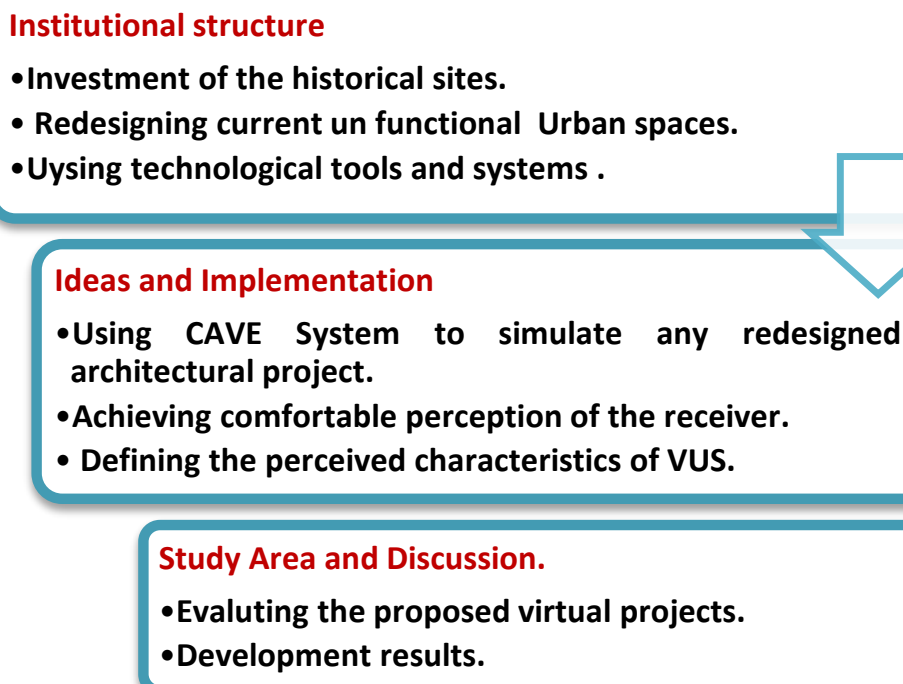

Fig.10. The Proposed Framework concerning the Upgrading Architectural Education.

\section{Results and discussion}

The paper presented a new vision for studying the benefit of proposing a virtual historical model of Elselsla study area to redesign and analyze it accurately using CAVE system. Further, if the proposed virtual model is comparing with the normal computer screen technology, the research reached to the following points:

1. A powerful instrument for updating the historical knowledge.

2. It is clear that, the $3 \mathrm{D}$ virtual model offers a complementary, intuitive access to complex $3 \mathrm{D}$ spatial models, broader audiences.

3. A tool for educating the historical sites without visiting it using VR technology that save time and cost especially in historical courses and design prnicibles for example architectural identity, architectural design concepts as a resource for student projects.

4. Redesigning the historical sites in the virtual model enables users to visualize and evaluate them with the new activities and services.

5. The proposed framework gives a better understanding of redesigning any historical site by presenting and analyzing this case.

\section{Conclusion}

The research reachs a number of conclusions showing the efficient performance of using the technical CAVE system in updating the architectural eduction that compared to the traditional techniques. This system improves the architectural education tools that in turn expand students' perceptions and help them in better visualizing of any current or proposed project. So, the students make more accurate design decisions, which saves time, effort and help them to better productivity. This procedure enhances the perception of virtual urban spaces of any urban project or redesigning of the 3D buildings especially the historical. The study presents the process of visualizing the virtual redesigned historical model at a case study model of Elselsla in Alexandria city in Egypt by proposing new activites and needed services. Furthermore; The proposed framework can be used at the local level with the capabilities available in Egypt which actually be applied for the better exploit of cultural heritage of the historical regions. Likewise; the study contributes to a comprehensive design process that support experts designers and also the architectural students in developing their perception of studying the historical courses with the new technologies. Also, the proposed study enhances the analysis study of the complex historical sites which need to upgrad for being landmarks that contributes in rising the local investment. The proposed virtual model can be tested and evaluated using the CAVE system before implementing it in the real world which save time, effort and cost that avoids any problem which would appear after the implention process of proposed improved projects. So, this proposed study benefits different stakeholders such as; architectural students in their syding course to be upgraded. Also, the study would help archeologists, expert designers, urban planners and different local authorities in their decision making of accurate studies before the implemention process in real world. 


\section{References}

Afrooz, Aida E., Russell Lowe, Simone Zarpelon Leao, and Chris Pettit 2018 3D and Virtual Reality for Supporting Redevelopment Assessment. Real Estate and GIS: The Application of Mapping Technologies. Routledge: 151.

Berardi, Umberto 2018 Aerogel-Enhanced Systems for Building Energy Retrofits: Insights from a Case Study. Energy and Buildings 159: 370-381.

Boeters, Roeland, Ken Arroyo Ohori, Filip Biljecki, and Sisi Zlatanova 2015 Automatically Enhancing CityGML LOD2 Models with a Corresponding Indoor Geometry. International Journal of Geographical Information Science 29(12): 2248-2268.

Christensen, Kenn, Gorm Rosenberg, Ulrich Bauer, Dhaval Doshi, and Elmar Pothmann 2018 Method for Manufacturing an Aerogel-Containing Composite and Composite Produced by That Method.

Goswami, Sumita, Suman Nandy, Jonas Deuermeier, et al. 2018 Green Nanotechnology: Green Nanotechnology from Waste Carbon-Polyaniline Composite: Generation of Wavelength-Independent Multiband Photoluminescence for Sensitive Ion Detection (Adv. Sustainable Syst. 1/2018). Advanced Sustainable Systems 2(1).

Gröger, Gerhard, Thomas H. Kolbe, Claus Nagel, and Karl-Heinz Häfele 2012 OGC City Geography Markup Language (CityGML) Encoding Standard.

Kuliga, Saskia, James Charlton, Hilal Fitri Rohaidi, et al. 2020 Developing a Replication of a Wayfinding Study. From a Large-Scale Real Building to a Virtual Reality Simulation. In German Conference on Spatial Cognition Pp. 126-142. Springer.

Lee, Dohyun, Youngmin Seo, Muhammad Saad Khan, et al. 2018 Use of Nanoscale Materials for the Effective Prevention and Extermination of Bacterial Biofilms. Biotechnology and Bioprocess Engineering: 1-10.

Maghool, Sayyed Amir Hossain, Seyed Hossein Iradj Moeini, and Yasaman Arefazar 2018 An Educational Application Based on Virtual Reality Technology for Learning Architectural Details: Challenges and Benefits. ArchNet-IJAR: International Journal of Architectural Research 12(3). Archnet: 246.

Stirling,

Dale

A.

2018 Nanotechnology Applications. In The Nanotechnology Revolution Pp. 281-434. Pan Stanford.

Su, Meng, Zhandong Huang, Yifan Li, et al. 2018 A 3D Self-Shaping Strategy for Nanoresolution Multicomponent Architectures. Advanced Materials 30(3): 1703963.

Tran, Thi Huong Giang, Johannes Otepka, Di Wang, and Norbert Pfeifer 2018 Classification of Image Matching Point Clouds over an Urban Area. International Journal of Remote Sensing 39(12). Taylor \& Francis: 4145-4169.

Venit,

Marjorie Susan

2002 Monumental Tombs of Ancient Alexandria: The Theater of the Dead. Cambridge University Press.

Afrooz, Aida E., Russell Lowe, Simone Zarpelon Leao, and Chris Pettit

2018 3D and Virtual Reality for Supporting Redevelopment Assessment. Real Estate and GIS: The Application of Mapping Technologies. Routledge: 151.

Berardi,

2018 Aerogel-Enhanced Systems for Building Energy Retrofits: Insights from a Case Study. Energy and Buildings 159: 370-381. 
Boeters, Roeland, Ken Arroyo Ohori, Filip Biljecki, and Sisi Zlatanova 2015 Automatically Enhancing CityGML LOD2 Models with a Corresponding Indoor Geometry. International Journal of Geographical Information Science 29(12): 2248-2268.

Christensen, Kenn, Gorm Rosenberg, Ulrich Bauer, Dhaval Doshi, and Elmar Pothmann 2018 Method for Manufacturing an Aerogel-Containing Composite and Composite Produced by That Method.

Goswami, Sumita, Suman Nandy, Jonas Deuermeier, et al. 2018 Green Nanotechnology: Green Nanotechnology from Waste Carbon-Polyaniline Composite: Generation of Wavelength-Independent Multiband Photoluminescence for Sensitive Ion Detection (Adv. Sustainable Syst. 1/2018). Advanced Sustainable Systems 2(1).

Gröger, Gerhard, Thomas H. Kolbe, Claus Nagel, and Karl-Heinz Häfele 2012 OGC City Geography Markup Language (CityGML) Encoding Standard.

Kuliga, Saskia, James Charlton, Hilal Fitri Rohaidi, et al. 2020 Developing a Replication of a Wayfinding Study. From a Large-Scale Real Building to a Virtual Reality Simulation. In German Conference on Spatial Cognition Pp. 126-142. Springer.

Lee, Dohyun, Youngmin Seo, Muhammad Saad Khan, et al. 2018 Use of Nanoscale Materials for the Effective Prevention and Extermination of Bacterial Biofilms. Biotechnology and Bioprocess Engineering: 1-10.

Maghool, Sayyed Amir Hossain, Seyed Hossein Iradj Moeini, and Yasaman Arefazar 2018 An Educational Application Based on Virtual Reality Technology for Learning Architectural Details: Challenges and Benefits. ArchNet-IJAR: International Journal of Architectural Research 12(3). Archnet: 246.

Stirling,

Dale

A.

2018 Nanotechnology Applications. In The Nanotechnology Revolution Pp. 281-434. Pan Stanford.

Su, Meng, Zhandong Huang, Yifan Li, et al. 2018 A 3D Self-Shaping Strategy for Nanoresolution Multicomponent Architectures. Advanced Materials 30(3): 1703963.

Tran, Thi Huong Giang, Johannes Otepka, Di Wang, and Norbert Pfeifer 2018 Classification of Image Matching Point Clouds over an Urban Area. International Journal of Remote Sensing 39(12). Taylor \& Francis: 4145-4169.

Venit,

2002 Monumental Tombs of Ancient Alexandria: The Theater of the Dead. Cambridge University Press. 